
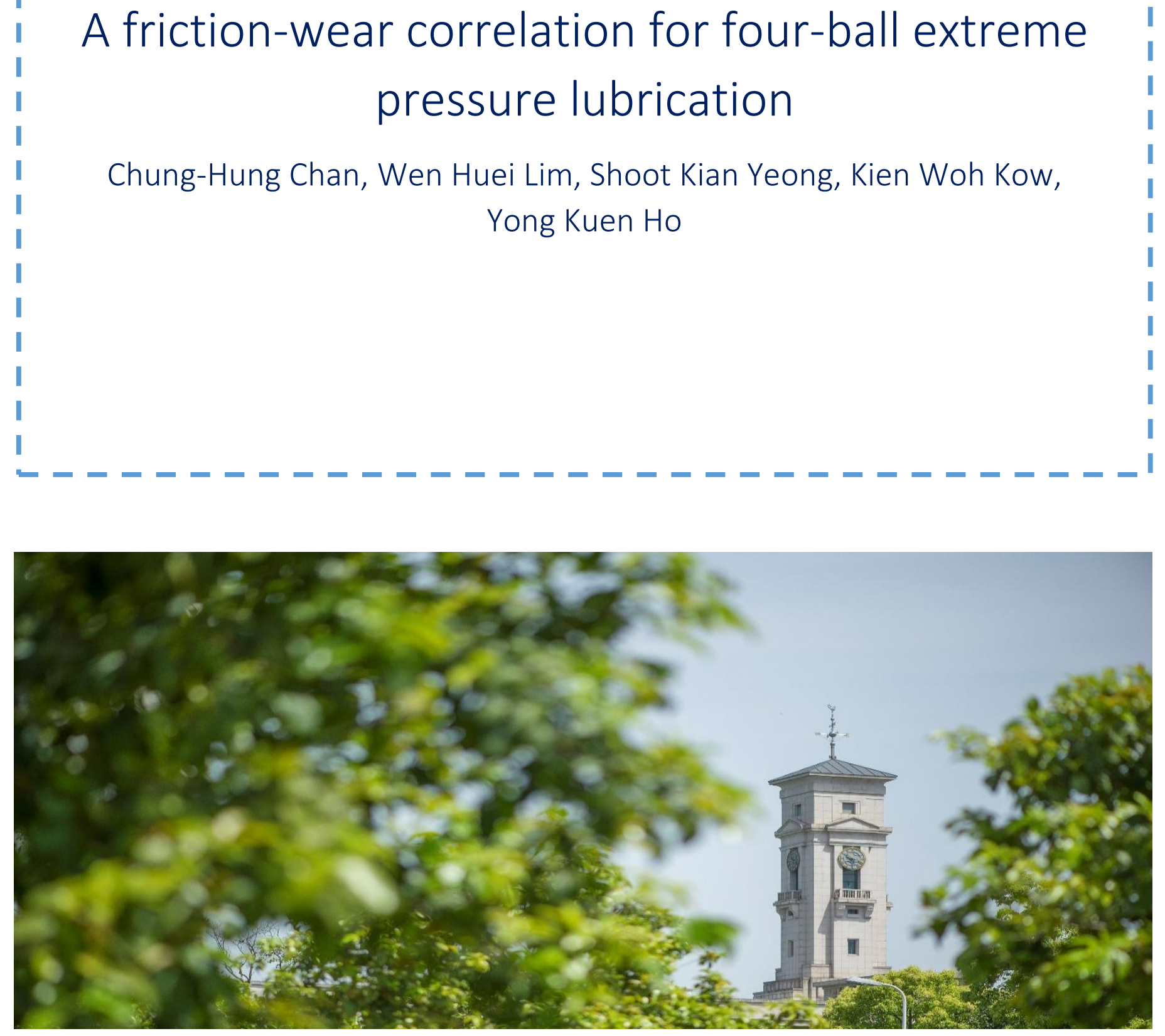
University of Nottingham Ningbo China, 199 Taikang East Road, Ningbo, 315100, Zhejiang, China.

First published 2020

This work is made available under the terms of the Creative Commons Attribution 4.0 International License:

http://creativecommons.org/licenses/by/4.0

The work is licenced to the University of Nottingham Ningbo China under the Global University Publication Licence:

https://www.nottingham.edu.cn/en/library/documents/research/global -university-publications-licence-2.0.pdf 


\section{A Friction-Wear Correlation for Four-Ball Extreme Pressure Lubrication}

Chung-Hung Chan ${ }^{\mathrm{a}, *}$, Wen Huei Lim ${ }^{\mathrm{a}}$, Shoot Kian Yeong ${ }^{\mathrm{a}}$, Kien Woh Kow ${ }^{\mathrm{b}}$

Yong Kuen Ho ${ }^{\text {c,d }}$

a Advanced Oleochemical Technology Division, Malaysian Palm Oil Board, 43000 Kajang, Selangor, Malaysia.

${ }^{\mathrm{b}}$ Department of Chemical and Environmental Engineering, Faculty of Science \& Engineering, The University of Nottingham Ningbo China, Ningbo 315100, PR China.

${ }^{\mathrm{c}}$ Chemical Engineering Discipline, School of Engineering, Monash University Malaysia, Jalan Lagoon Selatan, Bandar Sunway, 47500 Selangor, Malaysia.

${ }^{\mathrm{d}}$ Monash-Industry Palm Oil Education and Research Platform, Monash University Malaysia, Jalan Lagoon Selatan, Bandar Sunway, 47500 Selangor, Malaysia.

* Corresponding author, e-mail address: rykenz87@yahoo.com, chan@mpob.gov.my; Phone number: +603 8769 4315; Fax number: +603 89256197 


\section{ABSTRACT}

A first-ever friction-wear model for Four-Ball Extreme Pressure (EP) Lubrication test (ASTM D2783) is presented in this work. The model considers the rate of entropy generation and dissipation within the lubricated tribosystem to establish the friction-wear correlations for 12 lubricating oils comprising minerals, esters and other formulated oils. The correlations can be used to calculate the probability to pass/fail in the EP lubrication. The probability has similar trend as load-wear index from ASTM D2783 method. Besides, the friction-wear correlations allows quick estimation of EP performance of an unknown lubrication, upon comparing with that of an established one. The methods demonstrated here will help researchers or lubricant technologist to characterize the EP behavior quickly without over-relying on tribotester.

Keywords: weld point; extreme pressure; friction-wear correlation; Four-Ball; ASTM D2783 


\section{Introduction}

Tribological modelling has significantly contributed to the development of various applications: lubrication and friction, wear minimization, coating, additivation, functional lubricants, and surface material. It also helps in exploring new tribology area such as nano-tribology, biotribology, and nature-inspired adhesive contact. In order to keep up with the above developments, tribological modelling has advanced from a simple contact mechanic approach to a complex multiphysical approach, involving different time scale, length scale and conditional state (e.g. discrete, continuous) [1]. Despite the advancements, the fundamentals of friction and wear are still not fully understood. This is due to a lack of fundamental knowledge to describe and to validate the phenomena, and also due to the inability of experimental setup to observe the sliding interface in situ [1, 2]. The foregoing gaps call for the establishment of new tribological models to: a) shorten the computational time for predictions of high precision, and, b) prevent numerical simulations from becoming black boxes where the nuances of the phenomena are lost.

In lubricated tribology, the spectrum of lubrication models is widespread; but they all essentially depend on the mechanical characteristics of the system, lubrication regime, and the lubricant properties [3]. Traditionally, Reynolds Equation has been employed to analytically solve the classical contact problems such as Hydrodynamic Lubrication and ElastoHydrodynamic Lubrication [4-6]. The model aims to simulate friction coefficient, lubricant film thickness, and other rheological properties that account for the interactions between contact interfaces in specific lubricated conditions [4-7]. Hitherto, the model has been improvised to address non-Newtonian effect, surface roughness effect [8], surface topography effect [9], thermal effect [10, 11], and boundary lubrication behaviors [12]. The abovementioned model capabilities require the incorporation of other model frameworks and 
advanced approaches, e.g. asperity contact model to address the roughness effect in lubricated contact [8], finite element method to solve the lubricated contact problem involving complex domain of surface contacts $[9,13]$, and molecular dynamics simulation to investigate tribological phenomena in multiscale modelling $[14,15]$. Other than Reynolds Equation and its variants, other lubrication models in the literature revolve around regression analysis based on statistical approaches [16-19], empirical model driven by experimental observations [20, 21], and models derived from first principles [22-24].

The modelling of wear is usually performed after friction and lubrication modelling [25-27], although it can be conducted independently when the information of asperity contacts (or models), the mechanical properties of the surfaces, the wear mechanism and the lubricant actions are known [28-30]. As the understanding of wear mechanism even at macroscopic level is limited and incomplete [1], wear modelling is mostly conducted based on empirical approaches. Apart from the regression models and the complex model driven by hypothesized mechanism [26, 27, 30-32], one famous wear model is the Archard's wear model [33], or alternatively known as the Holm's wear model [30]. This model describes sliding wear based on the theory of asperity contacts. It is often characterized by the Archard wear coefficient, which can be obtained from experiments [33]. This model is usually integrated into multiphysics modelling to study the wear behaviors which result from lubricant-triboparts interaction.

In the literature, most friction and wear models were developed in such a way that they do not have the desired level of generality [34]. These models are undoubtedly useful to describe certain manifestations in tribology, but among themselves, the mutual dependence and the correlation between friction and wear remain unclear [34]. Since tribology can be seen as a 
thermodynamic system that deteriorates irreversibly with dissipation of energy [35-39], efforts have been made to unify the mechanisms of friction and wear based on the theory of NonEquilibrium Thermodynamics (NET). The NET approaches have been employed in the study of advanced surface materials [36, 40, 41] and sliding systems [35, 37, 42]. One of the simplest approach of NET is based on the assumption of local equilibrium [36], which states that in any small region of the occurring tribological system, its thermodynamic properties are related to the state variables in the same manner as in equilibrium. Another NET approach is known as the second law analysis [37, 43], which states that the lost available energy is directly proportional to the entropy production due to irreversibility in the process. The next type of NET is based on the observation of the degree of irreversibility of any condition in the system $[36,41,42]$, in which nonlinear flux-force relations are invoked to characterize a process that operates far from global equilibrium. Although NET offers a systematic approach to characterize a tribological system, more work is needed to incorporate real quantitative variables for practicality. Additionally, the approach should be lightweight, sufficiently robust and useful for the prediction of critical responses with a priori known precision.

In this work, for the first time the friction and the wear behaviors of Four-Ball extreme pressure (EP) test (ASTM D2783) are described using a single-equation model based on NET principles. The aims is to establish practical correlation and methods to estimate EP performance of lubricants in practice. This work presents the theoretical framework of the model in Section 2. Following that, a case study involving 12 lubricant samples is elucidated in Section 3, followed by the results validated over a broad range of lubrication conditions in Section 4. Finally, conclusions to this study are given in Section 5. 


\section{Modelling framework}

This model is constructed based on the following premises as shown in Fig. 1. Consider a tribosystem which consists of a pair of solid surfaces or triboparts, which are sliding against each other with lubrication at any operating condition. In this manner, the tribosystem is forced to operate at a non-equilibrium state. According to the second law of thermodynamics, the entropy production in the tribosystem is always positive. In this case, due to the generation of frictional energy during the sliding activity, the value of entropy in the tribosystem increases with time, in order to drive the tribosystem to the equilibrium state [40, 44]. If the tribosystem is not able to dissipate the frictional energy, it will then reach equilibrium state and thereafter its triboparts will be stopped or jammed. Naturally, there exists entropy dissipation mechanisms that take place within the tribosystem to compensate for the effect of entropy generation due to friction, so that the sliding activity prevails. The desired entropy dissipation mechanisms stem from the lubricant action, such as the conduction of frictional heat, the formation of highly ordered lubricant layer and the tribofilm formation due to additivation [45]. On the other hand, the undesired entropy dissipation is the wearing process, which could damage the triboparts and cause seizure [40]. The above dissipation mechanisms drive the tribosystem into a stationary state with minimal entropy production possible [45]. By balancing the rate of entropy production and dissipation within the tribosystem, a simple relationship between friction and wear can be established. 


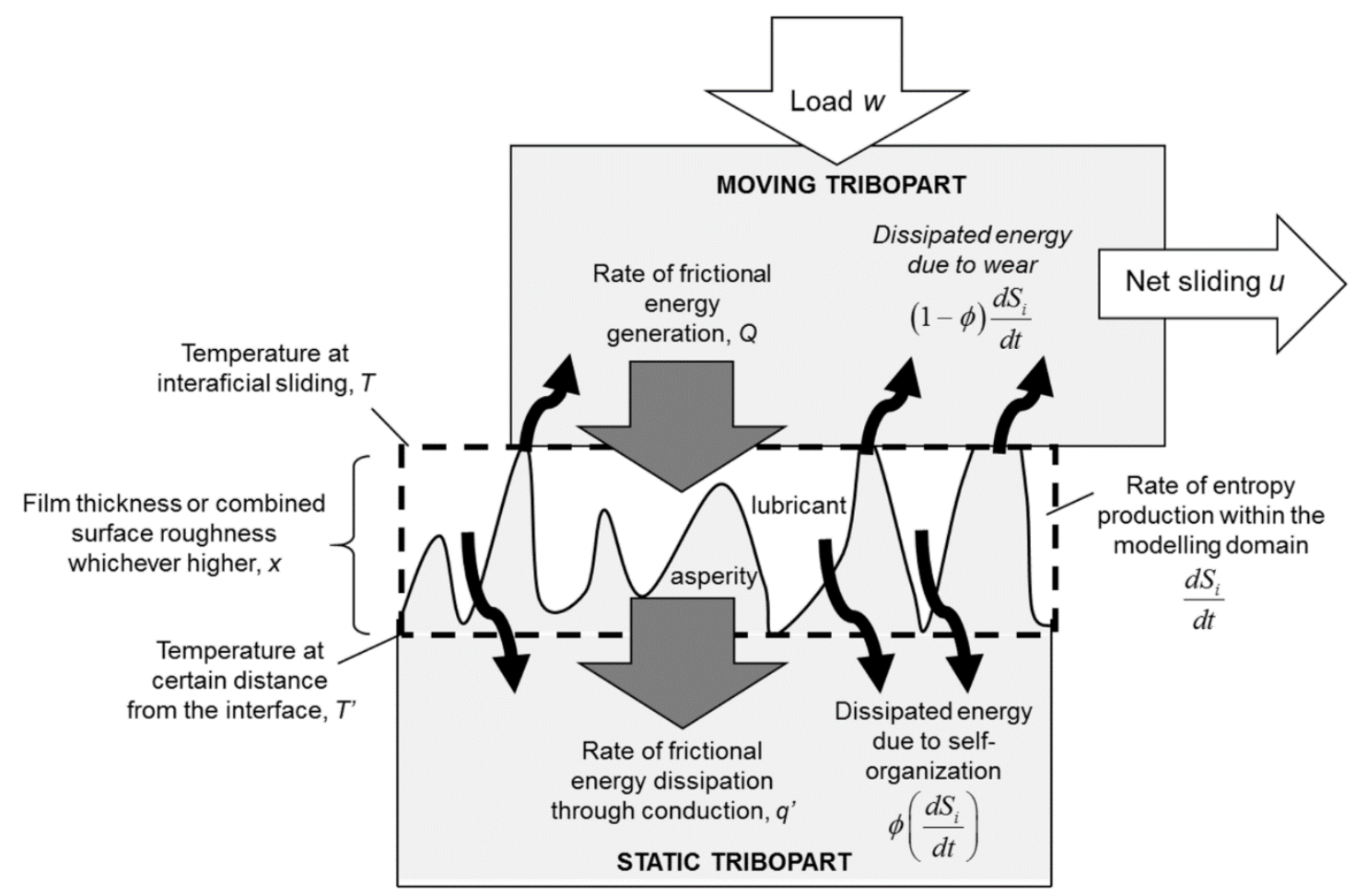

Fig. 1: Schematic diagram of Thermodynamic friction-wear model

\subsection{Entropy balance}

The total entropy production, $d S$ of a lubricated tribosystem under any operating conditions has the following components [38, 40]:

$$
d S=d S_{i}+d S_{e}+d S_{m}-\left|d S_{f}\right|-\left|d S_{w}\right|
$$

where $d S_{i}$ is the entropy production due to frictional sliding; $d S_{e}$ is the change of entropy due to heat transfer with the surrounding; $d S_{m}$ is the entropy production due to the generation of wear particles during friction; $d S_{f}$ is the decrease in entropy due to lubricant action; and $d S_{w}$ is the decrease in entropy as a result of the wearing process. Few assumptions are made to simplify this expression. First, it is assumed that the tribosystem is at a stationary state under constant operating condition $(d S / d t=0)$ [38]; Second, that the lubricant is kept within an enclosed cavity and there is no bulk movement of lubricant. As such, the heat transfer across the system (triboparts-lubricant system) is assumed to be negligible $\left(d S_{e}=0\right)$ as the magnitude 
of energy generated and dissipated within the system through friction and wear during short duration (i.e. $10 \mathrm{~s}$ ) is expected to be significantly larger than that of the heat loss to the surroundings (e.g. static air and neighbouring connection parts); and finally $d S_{m}$ is insignificant since the mass of wear particles are extremely low as compared to the overall mass of the triboparts [40]. With that, the rate of entropy production of the tribosystem at a stationary state can be approximated as follow.

$\frac{d S}{d t} \approx \frac{d S_{i}}{d t}-\left|\frac{d S_{f}}{d t}\right|-\left|\frac{d S_{w}}{d t}\right| \approx 0$

In practice, determination of $d S_{f}$ is difficult due to the complex lubricant-triboparts interaction. As such, $d S_{f}$ is taken as a portion of the total frictional energy $d S_{i}$, shown below:

$\frac{d S_{f}}{d t}=\frac{d S_{i}}{d t}(\phi)$

The friction and the wear components can be correlated by substituting Eq. (3) into Eq. (2), as follows:

$\frac{d S_{w}}{d t}=\frac{d S_{i}}{d t}(1-\phi)$

where $\phi$ is the dissipated portion of the total frictional energy due to the lubricant action.

\subsection{Entropy generation due to friction}

The expression for the rate of entropy generation due to friction, $d S_{i} / d t$ in Eq. (4) depends on the modelling domain of the tribosystem. The modelling domain considered here is the volume bounded by the interfacial contact area of triboparts and a certain depth of $x$ of the subsurface layer, which can be the lubricant film thickness or the combined surface roughness, as illustrated in Fig. 1. Following that, few assumptions are made similar to those of $[40,46]$. First, it is assumed that the ratio of frictional energy flux generated, $q$ to the dissipated flux through conduction, $q$ ' is directly proportional to the ratio of the temperature at the sliding 
interface, $T$ to the temperature at the certain sublayer depth $x, T^{\prime}$; and second, the conduction of frictional heat leaving the domain is driven by the average thermal conductivity of the domain, $k$ in the direction of $x$. With that, the rate of energy entering the domain, $Q$ and that leaving the domain, Q' can be expressed as Eq. (5) and Eq. (6), respectively.

$Q=\mu w v=U A_{c}\left(T-T^{\prime}\right)$

$Q^{\prime}=\left(1-\frac{Q}{U A_{c} T}\right) Q$

where $\mu$ is the friction coefficient; $w$ is the normal load; $v$ is the sliding speed; $U$ is the heat transfer coefficient of the domain, which equals $k / x ; A_{c}$ is the interfacial contact area; and $T$ is the lubrication temperature. Subtracting Eq. (6) with Eq. (5) and dividing by T, the rate of entropy built up within the domain can be expressed as:

$\frac{d S_{i}}{d t}=\frac{(\mu w v)^{2}}{A_{c} U T^{2}}$

Eq. (6) characterizes the deterioration of tribosystem based on the heat transfer coefficient $U$, similar to those reported in $[36,40,46]$, which represents the efficiency of the tribosystem (domain) to conduct the frictional heat away from the system.

\subsection{Entropy dissipation due to wear}

Since wear is usually accompanied by a change in the interfacial surface area, the use of surface energy to describe wear behaviour of the tribosystem is appropriate and can be found in [35, $37,43,45]$. Surface energy is the change of free energy when the surface area of a medium is increased by unit area. Using this approach, the rate of entropy dissipation due to wear can be described as follows:

$\frac{d S_{w}}{d t}=\frac{2 \gamma}{T}\left(b \times k_{w} w v\right)$ 
where $\gamma$ is the surface energy of the worn material; $b$ is the ratio of worn surface area to the worn volume; and $k_{w}$ is the specific wear rate. The ratio $b$ depends entirely on the geometry of contact (e.g. flat-on-flat, ball-on-flat). The ratio $b$ is needed for practicality to convert the model input from a worn area basis to a worn volume basis. The specific wear rate $k_{w}$ in Eq. (8) is usually determined experimentally by dividing the total wear volume with the normal force (load) and sliding distance $\left(\mathrm{mm}^{3} / \mathrm{Nm}\right)$.

\subsection{Friction-wear correlation in lubricated tribosystem}

A simple and direct equation relating friction and wear can be obtained by correlating Eq. (4, 7, and 8) as follows.

$$
k_{w}=\frac{\mu^{2}}{c U_{w}}
$$

where $c$ is the physical characterization parameter of the tribosystem $\left(c=2 A_{c} \gamma b T w^{-1} v^{-1}\right)$, and $U_{w}$ is the dissipative coefficient of tribosystem $\left(U_{w}=U(1-\phi)^{-1}\right)$. In this expression, the parameter $c$ can be calculated based on the physical property of the tribosystem and the operating conditions, whereas $U_{w}$ is the proportionality constant between the entropy dissipation capability of the lubrication and that of wear. In reality, both $U$ and $\phi$ are difficult to measure since they are interfacial properties. For simplicity, these parameters are lumped together as $U_{w}$ to denote the tendency of the tribosystem to cause wear.

\section{Case study}

This model was applied to study Four-Ball extreme pressure (EP) test for lubricating fluids (ASTM D2783) [47]. The model was validated based on the EP test results of 12 lubricants comprising of mineral oils, ester oils, and formulated lubricants. The detail of the experiments and the related model parameters are shown in Table 1. For the modelling in Four-Ball 
configuration, it is sensible to consider only one of the point contacts, i.e. the contact between the top spinning ball and one of the bottom stationary ball. The procedure to calculate the model parameters such as friction, wear and other constants for the Four-Ball EP test are shown in Appendix A. Note that this model is constructed to evaluate the internal entropy generation and dissipation within the triboparts-lubricant system, without considering the heat transfer between the system and the surrounding as described previously in Section 2.1. This is because the rate of entropy dissipation through wear is expected to be significantly larger than that through heat loss especially in such short duration (10 s). For the wear region in the Four-Ball EP test, the wear condition that is close to the last non-seizure load is mild $\left(k_{w}=1 \times 10^{-8}\right.$ to $1 \times 10^{-}$ ${ }^{6} \mathrm{~mm}^{3} / \mathrm{Nm}$ ); and the wear condition within the incipient seizure and immediate seizure regions can be classified as moderate/severe wear region $\left(k_{w}=1 \times 10^{-6}\right.$ to $\left.1 \times 10^{-2} \mathrm{~mm}^{3} / \mathrm{Nm}\right)$ and they usually have wear scar diameter above $1 \mathrm{~mm}$. Although the wear regions can be categorized based on Archard Dimensionless Wear Coefficient as reported in [48, 49], in this study the wear regions were categorized based on the specific wear rate $k_{w}$ because the two parameters have the same magnitude. They can be inter-converted based on the hardness of the triboparts material (order of $1 \times 10^{9} \mathrm{~Pa}$ for steel ball). 
Table 1: The EP test results and the model inputs

\begin{tabular}{|c|c|c|c|c|c|c|}
\hline lubricant & $\begin{array}{c}\text { viscosity } \\
\text { at } 40^{\circ} \mathrm{C} \\
(\mathrm{cP})^{\mathrm{a}}\end{array}$ & $\begin{array}{l}\text { machine } \\
\text { load, } L \\
(\mathrm{~kg})\end{array}$ & $\begin{array}{c}\text { average } \\
\text { frictional } \\
\text { torque, } F_{t} \\
(\mathrm{~kg}-\mathrm{mm})\end{array}$ & $\begin{array}{c}\text { wear } \\
\text { scar } \\
\text { diameter, } \\
d_{w} \\
(\mathrm{~mm})^{\mathrm{b}}\end{array}$ & $\begin{array}{c}\text { friction } \\
\text { coefficient, } \\
\mu\end{array}$ & $\begin{array}{c}\text { specific wear } \\
\text { rate, } k_{w} \\
\left(\mathrm{~mm}^{3} /(\mathrm{Nm})\right)\end{array}$ \\
\hline \multirow{5}{*}{$\begin{array}{l}\text { G1 SN150 } \\
\text { (mineral) }\end{array}$} & \multirow{5}{*}{26.4} & 50 & 24.57 & 0.35 & 0.1093 & $3.4 \mathrm{E}-08$ \\
\hline & & 63 & 38.94 & 1.72 & 0.1375 & 7.9E-05 \\
\hline & & 80 & 112.03 & 2.65 & 0.3116 & 3.5E-04 \\
\hline & & 100 & 100.51 & 2.63 & 0.2236 & 2.7E-04 \\
\hline & & 126 & 101.43 & 5.75 & 0.7381 & $5.0 \mathrm{E}-03$ \\
\hline \multirow{5}{*}{$\begin{array}{l}\text { G1 SN500 } \\
\text { (mineral) }\end{array}$} & \multirow{5}{*}{99.7} & 50 & 26.71 & 0.38 & 0.1188 & 8.9E-08 \\
\hline & & 63 & 29.18 & 0.63 & 0.1030 & $1.2 \mathrm{E}-06$ \\
\hline & & 80 & 70.08 & 1.92 & 0.1949 & $9.7 \mathrm{E}-05$ \\
\hline & & 100 & 88.33 & 2.22 & 0.1965 & $1.4 \mathrm{E}-04$ \\
\hline & & 126 & 453.92 & 5.70 & 0.8015 & 4.8E-03 \\
\hline \multirow{2}{*}{$\begin{array}{l}\text { G1 BS150 } \\
\text { (mineral) }\end{array}$} & \multirow{2}{*}{435.5} & 100 & 68.47 & 2.07 & 0.1523 & $1.0 \mathrm{E}-04$ \\
\hline & & 126 & 378.90 & 5.20 & 0.6690 & 3.3E-03 \\
\hline \multirow{6}{*}{$\begin{array}{l}\text { G2 SN150 } \\
\text { (mineral) }\end{array}$} & \multirow{6}{*}{25.7} & 40 & 16.99 & 0.42 & 0.0945 & $2.8 \mathrm{E}-07$ \\
\hline & & 50 & 21.54 & 1.5 & 0.0958 & 5.7E-05 \\
\hline & & 63 & 83.59 & 2.04 & 0.2952 & $1.6 \mathrm{E}-04$ \\
\hline & & 80 & 102.55 & 2.32 & 0.2852 & 2.1E-04 \\
\hline & & 100 & 151.43 & 2.63 & 0.3369 & 2.7E-04 \\
\hline & & 126 & 449.85 & 5.55 & 0.7943 & 4.3E-03 \\
\hline \multirow{4}{*}{$\begin{array}{c}\text { G2 SN500 } \\
\text { (mineral) }\end{array}$} & \multirow{4}{*}{71.0} & 63 & 21.99 & 0.43 & 0.0777 & $1.4 \mathrm{E}-07$ \\
\hline & & 80 & 78.77 & 2.32 & 0.2191 & 2.1E-04 \\
\hline & & 100 & 132.52 & 3.04 & 0.2948 & 4.9E-04 \\
\hline & & 126 & 422.48 & 5.70 & 0.7460 & 4.8E-03 \\
\hline \multirow{5}{*}{$\begin{array}{l}\text { Naphthenic } \\
\text { (mineral) }\end{array}$} & \multirow{5}{*}{17.9} & 50 & 28.82 & 0.39 & 0.1282 & $1.1 \mathrm{E}-07$ \\
\hline & & 63 & 48.30 & 0.66 & 0.1706 & $1.5 \mathrm{E}-06$ \\
\hline & & 80 & 109.86 & 2.46 & 0.3055 & 2.6E-04 \\
\hline & & 100 & 94.24 & 2.69 & 0.2097 & $3.0 \mathrm{E}-04$ \\
\hline & & 126 & 430.17 & 5.50 & 0.7596 & 4.2E-03 \\
\hline \multirow{4}{*}{$\begin{array}{c}\text { PETTO } \\
\text { (ester) }\end{array}$} & \multirow{4}{*}{57.6} & 63 & 21.30 & 0.44 & 0.0752 & $1.7 \mathrm{E}-07$ \\
\hline & & 80 & 29.66 & 0.46 & 0.0825 & $1.4 \mathrm{E}-07$ \\
\hline & & 100 & 60.86 & 1.93 & 0.1354 & 7.9E-05 \\
\hline & & 126 & 331.29 & 5.10 & 0.5850 & $3.1 \mathrm{E}-03$ \\
\hline \multirow{5}{*}{$\begin{array}{l}\text { PETC8/C10 } \\
\text { (ester) }\end{array}$} & \multirow{5}{*}{28.3} & 50 & 18.35 & 0.52 & 0.0817 & 6.3E-07 \\
\hline & & 63 & 26.45 & 0.57 & 0.0934 & 7.3E-07 \\
\hline & & 80 & 68.27 & 1.93 & 0.1899 & 9.9E-05 \\
\hline & & 100 & 53.82 & 1.93 & 0.1197 & 7.9E-05 \\
\hline & & 126 & 353.72 & 4.30 & 0.6246 & $1.6 \mathrm{E}-03$ \\
\hline \multirow{4}{*}{$\begin{array}{c}\text { TMP } \\
\text { C8/C10 } \\
\text { (ester) }\end{array}$} & \multirow{4}{*}{18.5} & 40 & 22.38 & 0.35 & 0.1245 & 7.7E-08 \\
\hline & & 50 & 27.25 & 0.47 & 0.1213 & 3.7E-07 \\
\hline & & 63 & 25.62 & 0.58 & 0.0905 & 8.0E-07 \\
\hline & & 80 & 75.03 & 2.42 & 0.2087 & $2.4 \mathrm{E}-04$ \\
\hline
\end{tabular}




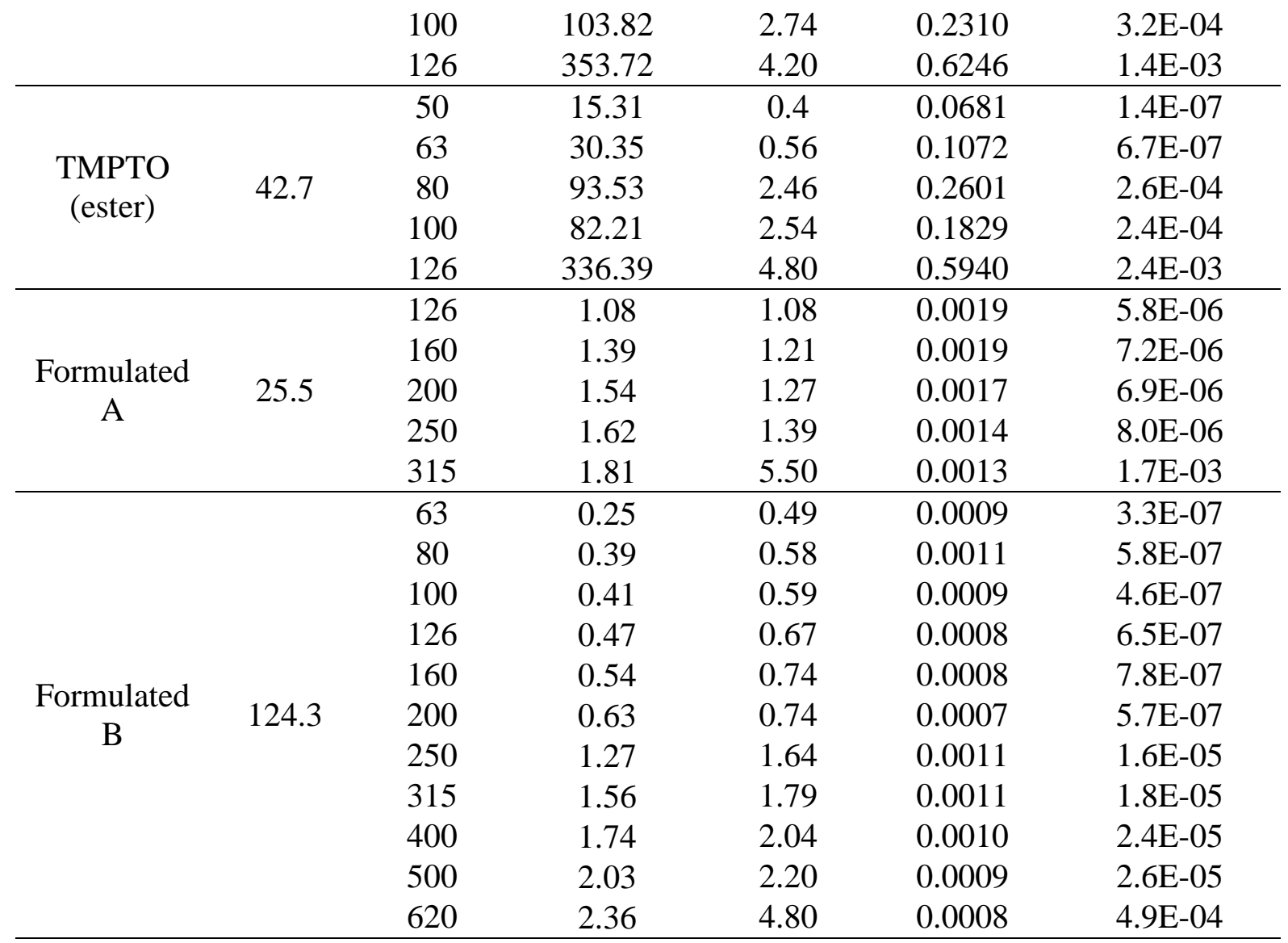

${ }^{a}$ Determined based on ASTM D445

${ }^{\mathrm{b}}$ Measured using DUCOM imaging device for non-welded ball. In the case of welded ball, the balls were forced to detach and then the scars were measured using vernier caliper

\section{Results and discussion}

\subsection{The characteristics of friction and wear in Four-Ball EP test}

The friction and the wear behaviors of a lubricated tribosystem are interrelated, in which wear increases with friction as observed in Fig. 2a and 2b. By substituting the predetermined parameter $c$ (Fig. 2c) into the friction-wear correlation in Eq. (9), the dissipative coefficient of tribosystem $U_{w}$ (Fig. 2d) can be obtained. Empirically, the change of $U_{w}$ was in accordance to the shift of the wear region of the triboparts, from a mild wear region to a moderate/severe wear region. At the mild wear region (e.g. $40 \mathrm{~kg}$ ), the tribosystem was able to dissipate the frictional entropy efficiently without inducing much wear, but the dissipation efficiency 
decreases with increasing loads. At one point when the wear falls within moderate/severe wear regions, the dissipation efficiency reached the minimum and remained unchanged at higher loads until weld point (e.g. 50-126 kg). It is interesting to note that the value of $U_{w}$ at the moderate/severe wear region is narrowly within $1.3 \times 10^{13}$ to $4.7 \times 10^{13} \mathrm{Wm}^{-2} \mathrm{~K}^{-1}$, which is much lower compared to $2.4 \times 10^{15} \mathrm{Wm}^{-2} \mathrm{~K}^{-1}$ at mild wear region. The values indicate that the lubrication efficiency to sustain the triboparts activity at EP condition (within moderate/severe wear region) was about constant and remained unchanged. At mild wear region, the lubrication efficiency changed with operating condition. This was due to the influences of lubricant film thickness (or viscosity effect) and lubrication regimes (e.g. mixed, boundary) associated to the mild wear region. As a result of the change of friction and wear characteristics, the change of lubrication efficiency in this case is expected.

(a)

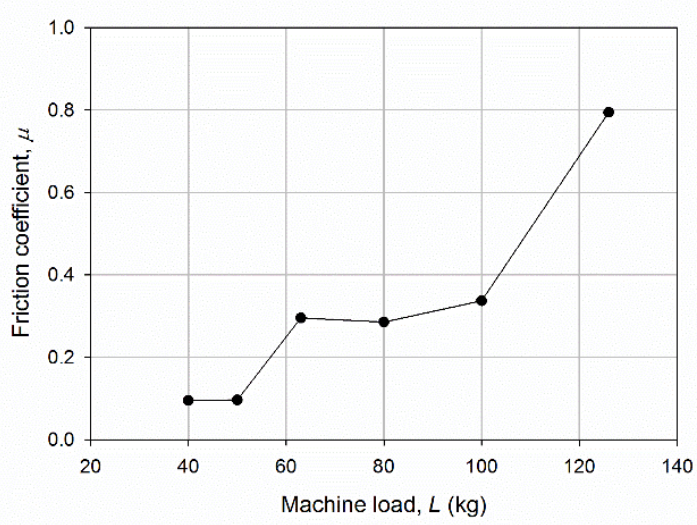

(c)

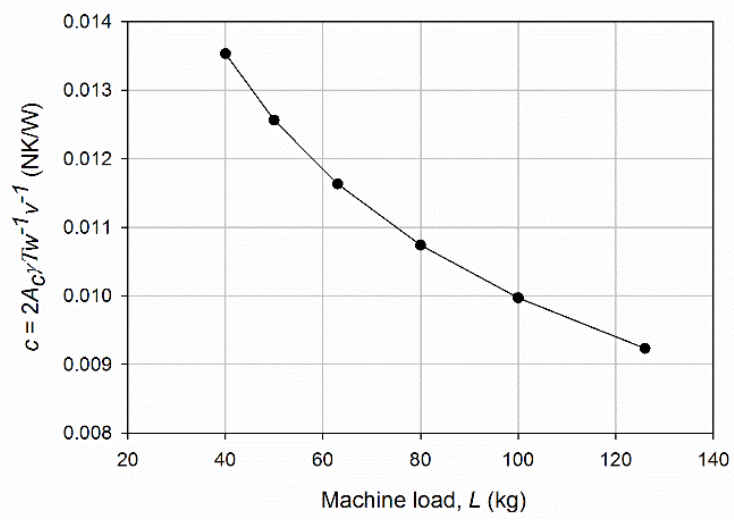

(b)

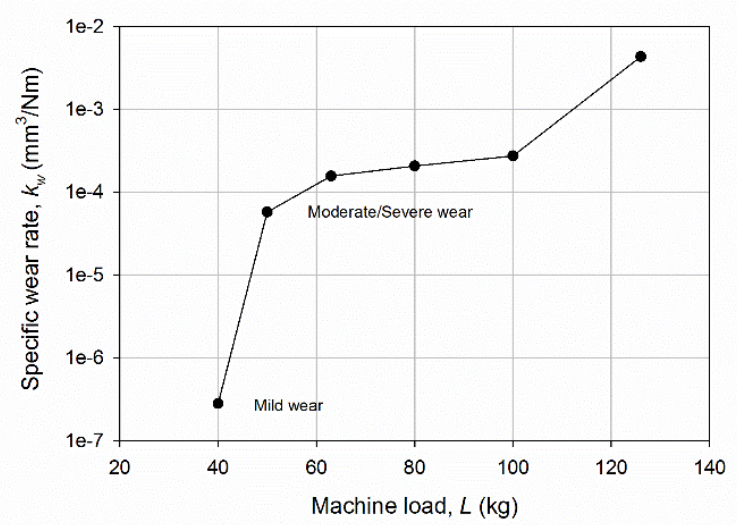

(d)

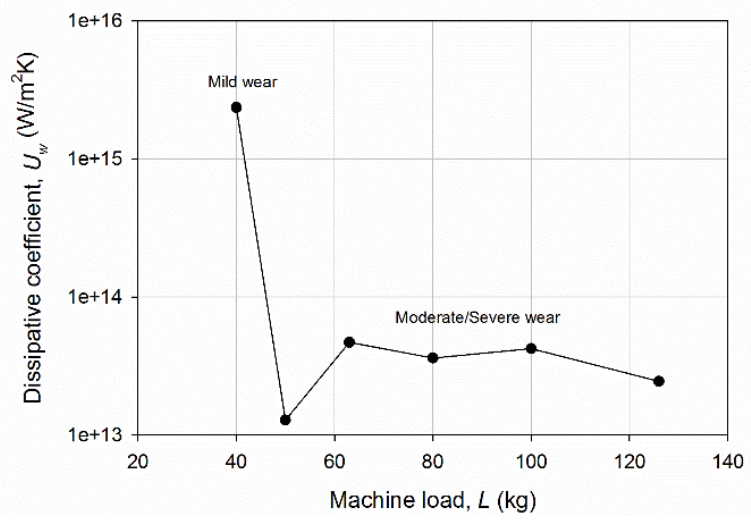

Fig. 2: EP test and modelling results of G2 SN150 mineral oil: (a) wear scar diameter; (b): specific wear rate; (c) characterization parameter of tribosystem; (d) dissipative coefficient 


\subsection{Predictive probability of pass/fail in EP test}

As the dissipative coefficient $U_{w}$ remained statistically constant throughout the moderate/severe wear region, it can be used to establish a simple friction-wear $\left(\mu-k_{w}\right)$ correlation for extreme pressure lubrication. The correlation can be obtained by calibrating Eq.

(9) based on the results in Fig. 2. Upon considering the range of the parameter $c$ (0.009-0.013 $\left.\mathrm{NKW}^{-1}\right)$, and the range of $U_{w}\left(1.3 \times 10^{13}\right.$ to $\left.4.7 \times 10^{13} \mathrm{Wm}^{-2} \mathrm{~K}^{-1}\right)$ in the moderate/severe wear region, the following $\mu-k_{w}$ relationship for base oil lubrication in EP condition was obtained:

$$
117<\frac{\mu^{2}}{k_{w}}<611
$$

This correlation indicates the friction to wear ratio of base oil lubrication at EP condition. It estimates the range of specific wear rate and hence wear scar diameter of base oil based on a specific friction coefficient, or vice versa. Besides, it serves as a reference to determine whether the lubricant passed or failed the EP test. There is a minimum friction coefficient threshold that the tribosystem must achieve before welding of triboparts happens (or having wear scar diameter greater than $4 \mathrm{~mm}$ ). Likewise, there is a maximum threshold of friction coefficient when the tribosystem welds. The above thresholds are tabulated in Table 2. 
Table 2: The minimum and maximum friction coefficient threshold of base oil lubrication at weld points

\begin{tabular}{cccc}
\hline Load $(\mathrm{kg})$ & $\begin{array}{c}\text { Specific wear rate at } \\
\text { weld point } \\
\left(\mathrm{mm}^{3} / \mathrm{Nm}\right)^{\mathrm{a}}\end{array}$ & $\begin{array}{c}\text { Minimum friction } \\
\text { coefficient threshold to } \\
\text { weld, } \mu_{\text {weld.min }}{ }^{\mathrm{a}}\end{array}$ & $\begin{array}{c}\text { Maximum friction } \\
\text { coefficient threshold to } \\
\text { weld, } \mu_{\text {weld.max }}{ }^{\mathrm{b}}\end{array}$ \\
\hline 40 & $3.66 \mathrm{E}-03$ & 0.6548 & 1.4964 \\
50 & $2.93 \mathrm{E}-03$ & 0.5857 & 1.3383 \\
63 & $2.33 \mathrm{E}-03$ & 0.5217 & 1.1922 \\
80 & $1.83 \mathrm{E}-03$ & 0.4629 & 1.0579 \\
100 & $1.46 \mathrm{E}-03$ & 0.4140 & 0.9461 \\
126 & $1.16 \mathrm{E}-03$ & 0.3688 & 0.8427 \\
160 & $9.15 \mathrm{E}-04$ & 0.3272 & 0.7477 \\
200 & $7.32 \mathrm{E}-04$ & 0.2926 & 0.6686 \\
250 & $5.85 \mathrm{E}-04$ & 0.2616 & 0.5979 \\
315 & $4.64 \mathrm{E}-04$ & 0.2330 & 0.5324 \\
400 & $3.65 \mathrm{E}-04$ & 0.2067 & 0.4723 \\
500 & $2.92 \mathrm{E}-04$ & 0.1847 & 0.4222 \\
620 & $2.35 \mathrm{E}-04$ & 0.1658 & 0.3789 \\
800 & $1.82 \mathrm{E}-04$ & 0.1458 & 0.3332 \\
\hline
\end{tabular}

${ }^{a}$ Determined based on $4 \mathrm{~mm}$ wear scar diameter

${ }^{\mathrm{b}}$ Calculated based on Eq. (10)

It is sensible to analyse pass/fail condition of the lubrication based on probabilistic approach, since tribology involves certain uncertainty due to complex physical and chemical mechanisms at different time and length scales. In this work, the procedure to calculate the pass/fail probability of the EP test is illustrated in Fig. 3. When the friction coefficient of a lubrication is below the minimum threshold, the lubrication passes the EP test. If the friction coefficient is within the minimum and maximum thresholds, the lubrication has a probability to fail. In this condition, the associated loads in the EP test is near or at the weld point of the lubrication. Beyond the maximum friction coefficient threshold, the lubrication is expected to have significant wear or causes welding of triboparts, and the associated loads could be beyond the 
weld point of the lubricant. The probability to fail for the lubrication at specified loading can be calculated as follows:

$P_{\text {weld }}=\frac{\log \left(\mu_{\exp } / \mu_{\text {weld.min }}\right)}{\log \left(\mu_{\text {weld.max }} / \mu_{\text {weld.min }}\right)} \times 100 \%$

where $\mu_{\text {exp }}, \mu_{\text {weld.min }}$ and $\mu_{\text {weld.max }}$ are the respective tested, minimum threshold and maximum threshold of friction coefficients. The probability $P_{\text {weld }}$ spans from 0 to $100 \%$ for $\mu_{\text {exp }}$ within the minimum and the maximum thresholds. When $\mu_{\exp }<\mu_{\text {weld.min }}$ (50-100 kg loads), the lubrication passed the EP test. At $126 \mathrm{~kg}$ load, the results showed that the triboparts is 93\% more likely to weld, because its friction coefficient (0.7943) exceeded the minimum threshold and was $7 \%$ below the maximum threshold. Therefore, $126 \mathrm{~kg}$ can be treated as the estimated weld point for the lubrication.

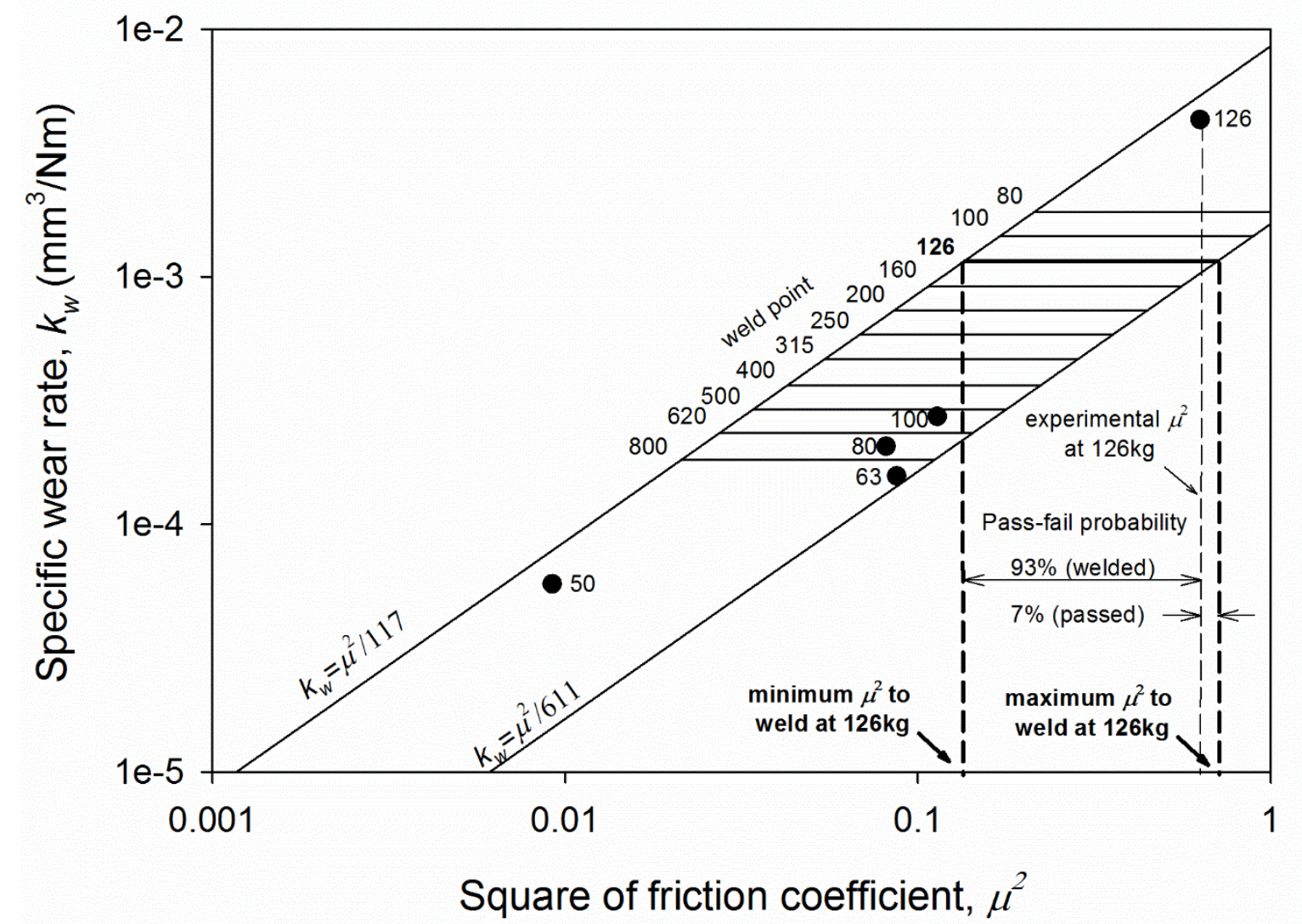

Fig. 3: Prediction of pass/weld of lubrication based on probabilistic approach 


\subsection{Prediction of EP performances: mineral vs. ester oils}

The pass probabilities ( $P_{\text {pass }}=1-P_{\text {weld }}$ ) of the mineral and the ester base oils (Table 1 ) at 126 kg load were calculated using Eq. (11). The results in Fig. 4 illustrated that the ester base oils $\left(P_{\text {pass }}=36-44 \%\right)$ gave better EP performance than the mineral base oils ( $\left.P_{\text {pass }}=6-28 \%\right)$, despite having a similar weld point of $126 \mathrm{~kg}$. When comparing $P_{\text {pass }}$ with the experimental load-wear index, which is an indicator obtained from ASTM D2783 to denote the capability of the lubrication to withstand extreme pressure condition; both $P_{\text {pass }}$ and load-wear index exhibited similar trends, but differed in the degree of change. Only one point (G1 SN500 oil) in the analysis was off the trend. Nevertheless, it is still within the span of the pass probability of the mineral oils. On the other hand, it was found that viscosity has certain impact on EP performance as in the case of G1 BS150 oil. High viscosity G1 BS150 oil (435.5 cP) had at least $40 \%$ better EP performance than other G1 base oils (26.4 and 99.7 cP), but still below that of the ester base oils. In this demonstration, this probabilistic approach to predict EP performance should be viewed as a useful estimation tool rather than an absolute deterministic one. The advantage of this approach is that the determination of pass/fail probability needs only 1 experimental friction coefficient data, whereas the load-wear index requires up to 10 experimental data points of wear at various loads. 


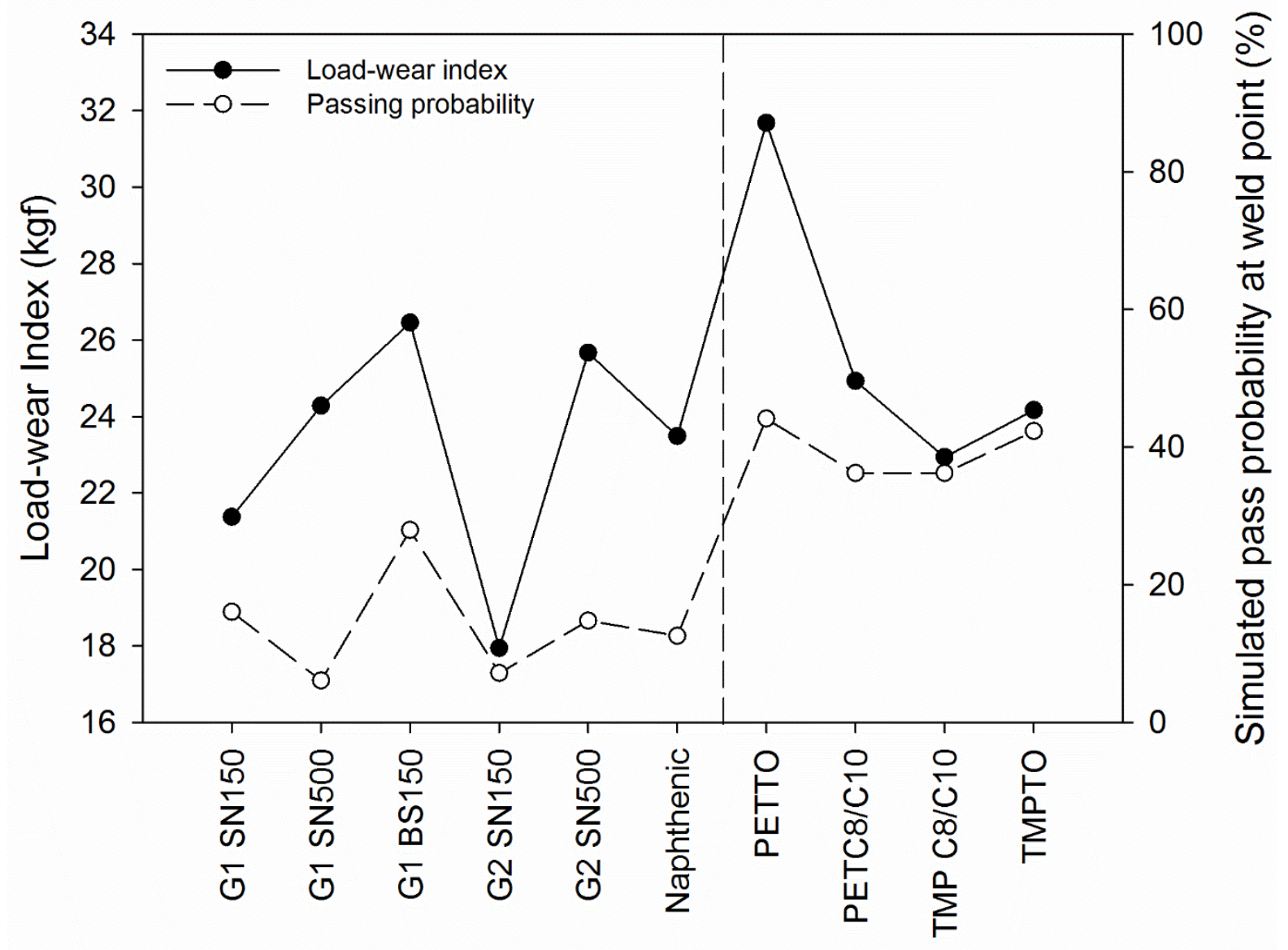

Base oils

Fig. 4: Comparison of the simulated pass probability at $126 \mathrm{~kg}$ weld point (1- $\left.P_{\text {weld }}\right)$ and the experimental load-wear index (ASTM D2783) for mineral and ester base oils

Both the mineral and the ester base oils exhibited similar friction-wear relationship as depicted in Fig. 5. This could be due to the similar entropy dissipation mechanisms and capabilities in both the lubrications. The two lubrications nonetheless exhibited slightly distinct EP performances as discussed previously in Fig. 4. The ester base oils gave slightly lower friction due to the anti-friction capability of the polar ester functional groups [3, 50]. As a result, they had smaller wear scar diameter since $k_{w}$ is proportional to $\mu^{2}$. Based on the model results, it seems that friction and wear are not mutually interacting. Rather, friction can be considered as an independent phenomenon due to the complex interaction between lubricant and triboparts; 
whereas wear is the dependent consequence, which is the final resolution of the tribosystem to balance out the entropy generation due to friction, whenever the entropy dissipation mechanism by lubricant action is deficient. The lubricant action in this context is not limited to that exhibited by base oils such as heat conduction, self-organization of lubricant molecules and tribofilm formation; but also includes those exhibited by lubricant additivation such as the formation of tribofilm layer due to adsorption or reaction.

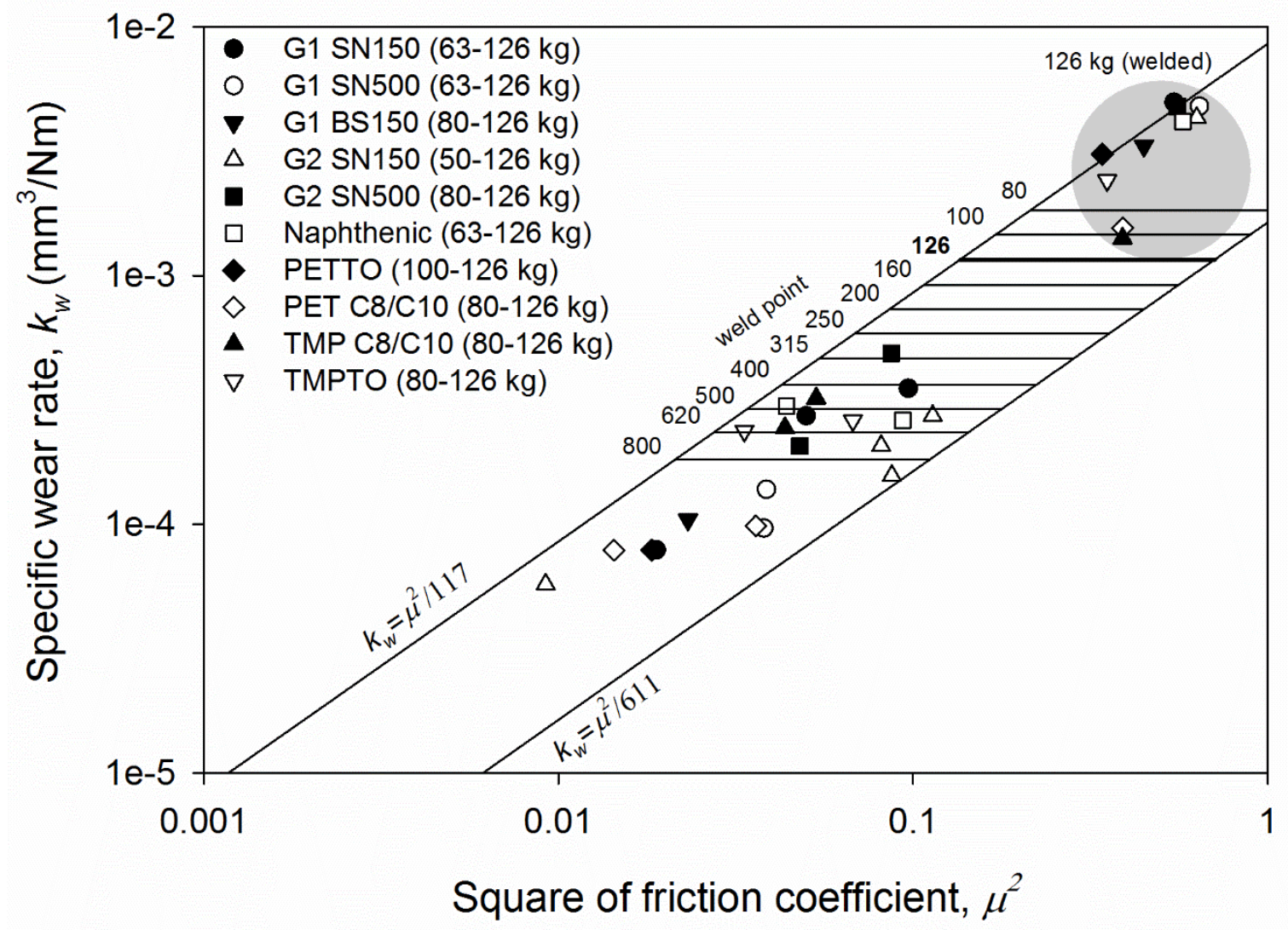

Fig. 5: Friction-wear relationship of mineral and ester base oils in extreme pressure test (ASTM D2783) 


\subsection{Characterization of tribological behavior of EP additives}

Lubricant additive is known to alter the interaction between lubricant and triboparts in certain ways, such as lower friction, wear prevention and so on [51]. From the model perspective, additivation is an additional entropy dissipation mechanism to sustain the activity of the triboparts. The friction-wear relationship of lubrication with additives is expected to be distinct from that of the base oils. The results in Fig. 6 illustrated that the formulated lubricants were able to generate lesser friction and to withstand higher loads as compared to that in the base oils. This observation hypothesized that EP performance and friction are interconnected, such that the lubricant that has higher EP performance (e.g. Formulated B) tends to have smaller friction coefficient in general.

If the tribosystem operates in low friction state, the rate of entropy generation due to friction decreases and the required entropy dissipation rate to sustain the activity also decreases. In this case, $U_{w}$ of the formulated lubricants (order of $10^{8}$ to $10^{10}$ ) is lesser than that in the case of base oils (order of $10^{13}$ ), indicating that the rate of dissipation of the former is much lesser. It should be noted that the order of magnitude of parameter $c$ in both cases are similar (order of $10^{-3}$ to $10^{-2}$ ). Because of the lower rate of entropy dissipation, the system can withstand higher loadings before reaching the capability limit of the lubrication to dissipate entropy. The friction-wear correlations in Fig. 6 cannot be regarded as complete or absolute tabulation, without considering the exhaustive list of lubricant base oil, additives and their countless combination. Nevertheless, the correlation is a useful tool to gauge the EP performance for lubricants, considering only few friction-wear data points in EP lubrication (moderate/severe wear region). Generally, a lubrication has better EP performance when its friction-wear data point is nearer to the upper left region of Fig. 6 . The position is governed by the dissipative coefficient $U_{w}$, which denotes the characteristics of lubricant action in the sliding activity. The 
above relationships are relevant within the moderate/severe wear region. For mild wear region, model calibration is required to find relevant $U_{w}$ for further characterizations.

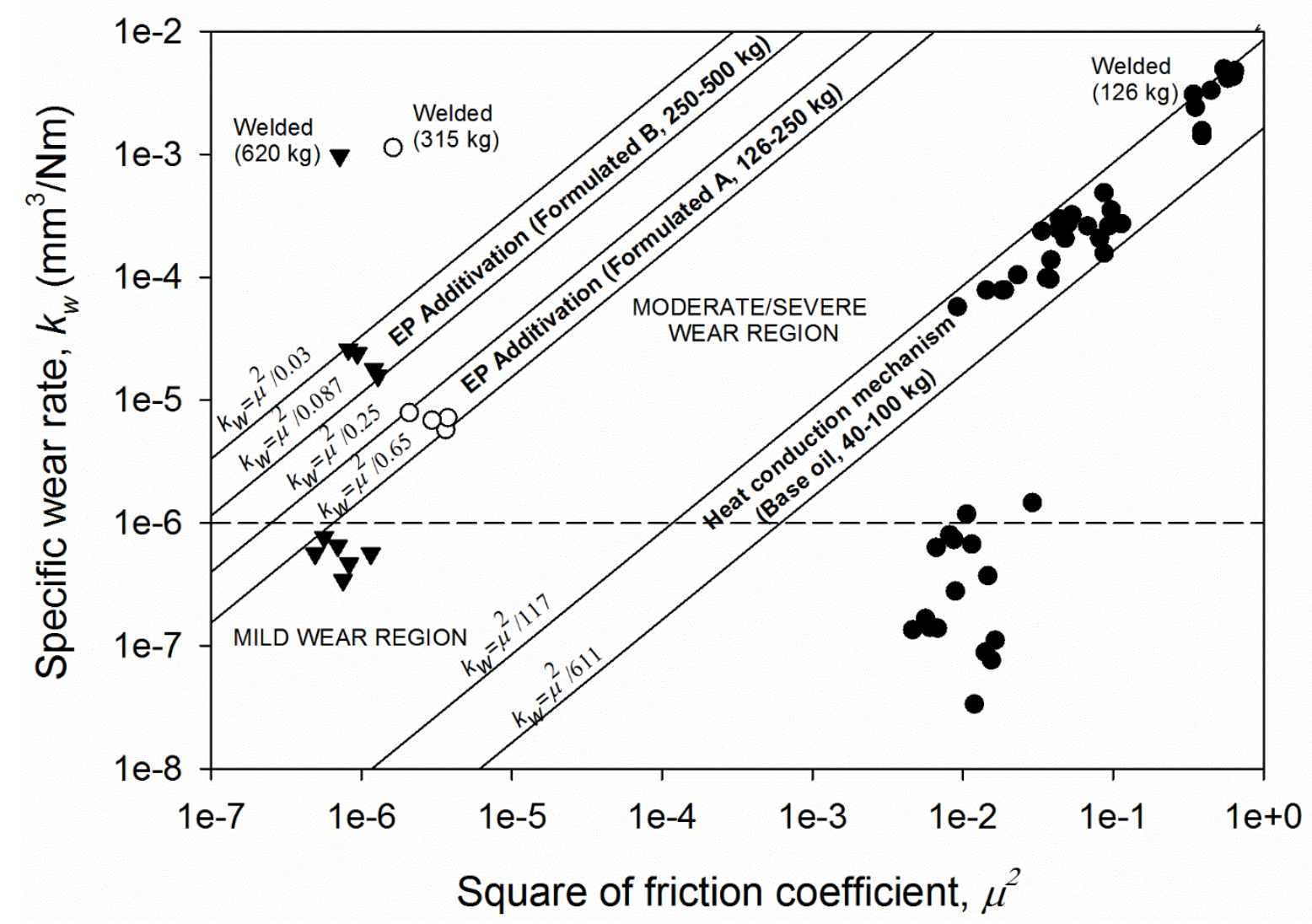

Fig. 6: Friction-wear relationship of base oils and formulated oils in extreme pressure test (ASTM D2783)

\section{Conclusion}

In this work, for the first time, a single-equation friction-wear model based on entropy balance was developed and validated based on Four-Ball extreme pressure (EP) test (ASTM D2783). The resulting friction-wear correlation is practical and easy to use, since it involves only one parameter namely the dissipative coefficient $U_{w}$. This intrinsic parameter describes many aspects of the tribosystem, such as the friction-wear relationship, the lubrication capability to sustain triboparts activity, and the tendency to wear. The applications of $U_{w}$ demonstrated in 
this work for quick characterization and estimation of EP performance is feasible without overreliance on tribotester, and they are closely related to the performance indicator of the standard method. With the fundamentals presented in this work, more study regarding $U_{w}$ for various formulation or lubricant components can be explored.

\section{Acknowledgement}

The authors thank the Director-General of MPOB for permission to publish this work.

\section{APPENDIX A. Calculation of model parameter in the Four-Ball Extreme Pressure Test}

The model parameters in Four-Ball configuration is calculated based on one of the point contacts as in $[52,53]$. For a given machine loading, $L(\mathrm{~kg})$, few contact parameters can be determined.

The normal load on one bottom ball (kg):

$$
L_{N}=0.408 L
$$

The contact diameter between the top ball and the bottom ball (mm):

$$
d_{H}=0.0873 L^{1 / 3}
$$

The contact area between the top ball and the bottom ball $\left(\mathrm{mm}^{2}\right)$ :

$$
A_{c}=\pi d_{H}^{2} / 4
$$

According to ASTM D2783, the rotational speed of the top ball, $\omega$ is $1760 \mathrm{rpm}$. Knowing the distance from the center of the contact surfaces of the underlying balls to the axis of rotation, $x$ is about $3.67 \mathrm{~mm}$ according to the machine specification, the sliding speed can be calculated as follow.

The sliding velocity $\left(\mathrm{ms}^{-1}\right)$ :

$$
v=2 \pi \omega x / 60000=0.676 \mathrm{~ms}^{-1}
$$


The lubrication temperature is set to room temperature in this modelling study.

In Four-Ball Tribotester, the friction data is reported as friction torque, $F_{t}(\mathrm{~kg}-\mathrm{mm})$. To convert it to friction coefficient, the following formula from IP-239 [54] is used.

Friction coefficient:

$\mu=0.22248 F_{T} / L$

The average friction coefficient during the sliding duration of $10 \mathrm{~s}$ (as in ASTM D2783) is considered.

In practice, the average wear scar diameter of the bottom balls, $d_{w}(\mathrm{~mm})$ is measured and reported. It can be used to calculate other wear parameter as in [52, 55, 56].

Wear volume of one bottom ball $\left(\mathrm{mm}^{3}\right)$ :

$V_{w}=1.55 \times 10^{-2} d_{w}^{4}-1.07 \times 10^{-5} L d_{w}$

Specific wear rate $\left(\mathrm{mm}^{3} \mathrm{~N}^{-1} \mathrm{~m}^{-1}\right)$

$k_{w}=V_{w} /\left(9.81 L_{N} v t\right)$

In this model, finding the ratio of worn surface area to the worn volume is crucial when estimating the change of surface free energy during wear. The surface free energy of AISI 52100 steel ball is about $1.95 \mathrm{~J} / \mathrm{m}^{2}$ (based on Fe as in [57]). The ratio $b$ can be calculated based on the geometry of a spherical cap with sphere radius, $r$ of $6.35 \mathrm{~mm}$ (steel ball) and certain height, $h$. In this manner, the volume of the spherical cap can be seen as the wear volume $V_{w}$; the base area of the spherical cap as the worn surface area $A_{w}$ characterized by the wear scar diameter $d_{w}$; and the height $h$ as the depth of the worn volume. The above parameters can be calculated using the following equations.

Volume of the spherical cap $\left(\mathrm{mm}^{3}\right)$ : 
$V_{w}=\pi h^{2}(3 r-h) / 3$

Base area of the spherical cap $\left(\mathrm{mm}^{2}\right)$ :

$$
A_{w}=\frac{\pi\left(d_{w}\right)^{2}}{4}
$$

The relationship between the depth of worn area, $h$ and wear scar diameter, $d_{w}$ :

$$
h^{2}-2 r h+\frac{d_{w}{ }^{2}}{4}=0
$$

The ratio of worn surface area to the worn volume of a stationary ball $\left(\mathrm{mm}^{-1}\right)$ :

$b=\frac{\int_{h_{0}}^{h_{1}} \frac{A_{w}}{V_{w}} d h}{h_{1}-h_{0}}$

As the ratio of worn surface area to the worn volume changes with the wear progression, an average worn area-volume ratio, $b$ to denote the wear characteristics within EP lubrication is needed for model simplicity. The average ratio b value is calculated to be around $18 \mathrm{~mm}^{-1}$, upon integrating $A_{w} / V_{w}$ over $h$ within the limits of moderate/severe wear region using Eq. (A.11). In this study, the limits of integration (i.e. $h_{0}=0.02 \mathrm{~mm}$ and $h_{1}=0.32 \mathrm{~mm}$ ) are calculated based on the typical range of $d_{w}$ (i.e. $1 \mathrm{~mm}$ to $4 \mathrm{~mm}$ ) using Eq. (A.10). Note that the depth of worn area $(h)$ in practice rarely exceeds $1 \mathrm{~mm}$ unless the balls weld.

\section{REFERENCES}

[1] Vakis AI, Yastrebov VA, Scheibert J, Nicola L, Dini D, Minfray C, et al. Modeling and simulation in tribology across scales: An overview. Tribol Int 2018;125:169-99.

[2] Vanossi A, Manini N, Urbakh M, Zapperi S, Tosatti E. Colloquium: Modeling friction: From nanoscale to mesoscale. Rev Mod Phys 2013;85:529-52.

[3] Chan C-H, Tang SW, Mohd NK, Lim WH, Yeong SK, Idris Z. Tribological behavior of biolubricant base stocks and additives. Renew Sust Energ Rev 2018;93:145-57. 
[4] Evans HP, Snidle RW, Sharif KJ. Deterministic mixed lubrication modelling using roughness measurements in gear applications. Tribol Int 2009;42:1406-17.

[5] Larsson R. Modelling the effect of surface roughness on lubrication in all regimes. Tribol Int 2009;42:512-6.

[6] Li S, Kahraman A. A mixed EHL model with asymmetric integrated control volume discretization. Tribol Int 2009;42:1163-72.

[7] Allmaier H, Priestner C, Six C, Priebsch HH, Forstner C, Novotny-Farkas F. Predicting friction reliably and accurately in journal bearings-A systematic validation of simulation results with experimental measurements. Tribol Int 2011;44:1151-60.

[8] Allmaier H, Priestner C, Reich FM, Priebsch HH, Forstner C, Novotny-Farkas F. Predicting friction reliably and accurately in journal bearings - The importance of extensive oil-models. Tribol Int 2012;48:93-101.

[9] Ripoll MR, Podgornik B, Vižintin J. Finite element analysis of textured surfaces under reciprocating sliding. Wear 2011;271:952-9.

[10] Li S, Kahraman A, Anderson N, Wedeven LD. A model to predict scuffing failures of a ball-on-disk contact. Tribol Int 2013;60:233-45.

[11] Ouyang T, Huang H, Zhang N, Mo C, Chen N. A model to predict tribo-dynamic performance of a spur gear pair. Tribol Int 2017;116:449-59.

[12] Mukchortov I, Zadorozhnaya E, Polyacko E. Transitional Friction Regime Modeling under Boundary Lubrication Conditions. Procedia Eng 2017;206:725-33.

[13] Hao L, Meng Y. Numerical Prediction of Wear Process of an Initial Line Contact in Mixed Lubrication Conditions. Tribol Lett 2015;60:31.

[14] Ghaffari MA, Zhang Y, Xiao S. Multiscale modeling and simulation of rolling contact fatigue. Int J Fatigue 2018;108:9-17. 
[15] Godlevskiy VA, Blinov OV. Computing of the Molecular Orientation State of the Lubrication Layer. Procedia Eng 2016;150:584-9.

[16] Baskar S, Sriram G, Arumugam S. The Use of D-optimal Design for Modeling and Analyzing the Tribological Characteristics of Journal Bearing Materials Lubricated by NanoBased Biolubricants. Tribol T 2016;59:44-54.

[17] Xiong S, Sun J, Xu Y, Yan X. QSPR Models for the Prediction of Friction Coefficient and Maximum Non-Seizure Load of Lubricants. Tribol Lett 2015;60:13.

[18] Simonovic K, Kalin M. Methodology of a statistical and DOE approach to the prediction of performance in tribology - A DLC boundary-lubrication case study. Tribol Int 2016;101:10-24.

[19] Weinebeck A, Kaminski S, Murrenhoff H, Leonhard K. A new QSPR-based prediction model for biofuel lubricity. Tribol Int 2017;115:274-84.

[20] Hu Y, Wang L, Politis DJ, Masen MA. Development of an interactive friction model for the prediction of lubricant breakdown behaviour during sliding wear. Tribol Int 2017;110:370-7.

[21] Zhou C, Hu B, Qian X, Han X. A novel prediction method for gear friction coefficients based on a computational inverse technique. Tribol Int 2018;127:200-8.

[22] Chong WWF, Ng JH. An atomic-scale approach for biodiesel boundary lubricity characterisation. Int Biodeterior Biodegradation 2016;113:34-43.

[23] Ghanbarzadeh A, Wilson M, Morina A, Dowson D, Neville A. Development of a new mechano-chemical model in boundary lubrication. Tribol Int 2016;93:573-82.

[24] Lyashenko IA, Khomenko AV. Thermodynamic Theory of Two Rough Surfaces Friction in the Boundary Lubrication Mode. Tribol Lett 2012;48:63-75.

[25] Li S, Anisetti A. A tribo-dynamic contact fatigue model for spur gear pairs. Int J Fatigue 2017;98:81-91. 
[26] Zhang J-g, Liu S-j, Fang T. On the prediction of friction coefficient and wear in spiral bevel gears with mixed TEHL. Tribol Int 2017;115:535-45.

[27] Gao L, Hua Z, Hewson R. Can a “pre-worn” bearing surface geometry reduce the wear of metal-on-metal hip replacements? - A numerical wear simulation study. Wear 2018;406407:13-21.

[28] Bosman R, Schipper DJ. Mild Wear Prediction of Boundary-Lubricated Contacts. Tribol Lett 2011;42:169-78.

[29] Bosman R, Schipper DJ. Mild wear maps for boundary lubricated contacts. Wear 2012;280-281:54-62.

[30] Mishina H, Hase A. Wear equation for adhesive wear established through elementary process of wear. Wear 2013;308:186-92.

[31] Tan Y, Zhang L, Hu Y. A Wear Model of Plane Sliding Pairs Based on Fatigue Contact Analysis of Asperities. Tribol T 2015;58:148-57.

[32] Cao S, Guadalupe Maldonado S, Mischler S. Tribocorrosion of passive metals in the mixed lubrication regime: theoretical model and application to metal-on-metal artificial hip joints. Wear 2015;324-325:55-63.

[33] Meng HC, Ludema KC. Wear models and predictive equations: their form and content. Wear 1995;181-183:443-57.

[34] Banjac M, Vencl A, Otović S. Friction and Wear Processes - Thermodynamic Approach. Tribol Ind 2014;36:341-7.

[35] Ramalho A, Miranda JC. The relationship between wear and dissipated energy in sliding systems. Wear 2006;260:361-7.

[36] Fox-Rabinovich G, Veldhuis SC, Kovalev AI, Wainstein DL, Gershman IS, Korshunov $\mathrm{S}$, et al. Features of self-organization in ion modified nanocrystalline plasma vapor deposited AlTiN coatings under severe tribological conditions. J Appl Phys 2007;102:074305. 
[37] Abdel-Aal HA. Influence of frictional energy dissipation on wear regime transition in dry tribo-systems. International Journal of Materials and Product Technology. 2010;38:78-92. [38] Amiri M, Khonsari MM. On the Thermodynamics of Friction and Wear-A Review. Entropy 2010;12:1021.

[39] Gershman I, Gershman E, Mironov A, Fox-Rabinovich G, Veldhuis S. Application of the Self-Organization Phenomenon in the Development of Wear Resistant Materials—A Review. Entropy. 2016;18:385.

[40] Fox-Rabinovich G, Totten GE. Self-Organization During Friction: Advanced SurfaceEngineered Materials and Systems Design. New York: CRC Press; 2006.

[41] Fox-Rabinovich G, Gershman I, Yamamoto K, Biksa A, Veldhuis S, Beake B, et al. Self-Organization during Friction in Complex Surface Engineered Tribosystems. Entropy 2010;12:275.

[42] Jing H-D, Zhang X-J, Tian Y, Meng Y-G. Thermodynamic analysis of lubrication considering solid-liquid interface interaction. Acta Phys Sin 2015;64:0168101.

[43] Bryant MD. Entropy and dissipative processes of friction and wear. FME T 2009;37:5560.

[44] Nosonovsky M, Mortazavi V. Friction-Induced Vibrations and Self-Organization: Mechanics and Non-Equilibrium Thermodynamics of Sliding Contact. Boca Raton: CRC Press; 2013.

[45] Nosonovsky M. Entropy in Tribology: in the Search for Applications. Entropy 2010;12:1345.

[46] Nosonovsky M. Self-organization at the frictional interface for green tribology. Philos. Trans. Royal Soc. A 2010;368:4755-74.

[47] ASTM D2783, Standard Test Method for Measurement of Extreme-Pressure Properties of Lubricating Fluids (Four-Ball Method). West Conshohocken 2014 
[48] Dodiya VK, Parmar JP. A Study of Various Wear Mechanism and its Reduction Method. Int J Innov Res Sci Eng Technol 2016;2:242-8.

[49] Kato K. Classification of wear mechanisms/models. P I Mech Eng J-J Eng 2002;216:349-55.

[50] Abd Maurad Z, Yeong SK, Idris Z, Ishak SA. Combined Esterification and Short-Path Distillation for High-Purity Pentaerythritol Ester from Palm Kernel for Biolubricants. J Am Oil Chem Soc 2018;95:1421-9.

[51] Nurul MA, Shahrullalail S, Teng HW. Alternative lubricants: Study on Palm Oil-Based Lubricants in Metal Forming Process. J. Oil Palm Res 2016;28:93-103.

[52] Sethuramiah A. Tribological evaluation methodologies. In: Sethuramiah A, editor. Lubricated Wear: Science and Technology Volume 42, Elsevier Science Serials; 2003, p. 203-34.

[53] Czichos H, Kirschke K. Investigations into film failure (transition point) of lubricated concentrated contacts. Wear 1972;22:321-36.

[54] IP 239. Determination of extreme pressure and anti-wear properties of lubricating fluids and greases - Four ball method. London 2014.

[55] Wright MS, Jain VK, Saba CS. Wear rate calculation in the four-ball wear test. Wear 1989;134:321-34.

[56] I-Ming F. A new approach in interpreting the four-ball wear results. Wear 1962;5:27588.

[57] Inman MC, Tipler HR. Interfacial energy and composition in metals and alloys. Metall Rev 1963;8:105-66. 


\section{Figure Captions}

Fig. 1: Schematic diagram of Thermodynamic friction-wear model

Fig. 2: EP test and modelling results of G2 SN150 mineral oil: (a) wear scar diameter; (b):

specific wear rate; (c) characterization parameter of tribosystem; (d) dissipative coefficient

Fig. 3: Prediction of pass/weld of lubrication based on probabilistic approach

Fig. 4: Comparison of the simulated pass probability at $126 \mathrm{~kg}$ weld point $\left(1-P_{\text {weld }}\right)$ and the experimental load-wear index (ASTM D2783) for mineral and ester base oils

Fig. 5: Friction-wear relationship of mineral and ester base oils in extreme pressure test (ASTM D2783)

Fig. 6: Friction-wear relationship of base oils and formulated oils in extreme pressure test (ASTM D2783) 